\title{
Different People Different Styles: Impact of Personality Style in Web Sites Credibility Judgement
}

\author{
Rahayu Ahmad ${ }^{1}$, Jieyu Wang ${ }^{1}$, Karoly Hercegfi ${ }^{2}$, and Anita Komlodi ${ }^{1}$ \\ ${ }^{1}$ Department of Information Systems, University of Maryland Baltimore County \\ ${ }^{2}$ Budapest University of Technology and Economics, Hungary \\ \{arahayu1, wajieyu1, komlodi\} @umbc. edu, \\ Hercegfi@erg.bme.hu
}

\begin{abstract}
Reliance on the Internet as a source of information has increased dramatically in recent years among information seekers. The reliability of information on the Internet can sometimes be questionable due to the absence of an editorial function. Users need to carefully consider the quality of the information before using it. The goal of this research was to study the process of credibility evaluation by users. We examined how personality styles influence the way people make credibility judgments when they are browsing online. Our results show that thinkers' evaluation style were more fact based than intuitive users who relied more on their initial impression and prior experience with the websites. Perceivers gathered information from various sources before trusting information and forming perception on the credibility of authors and websites. Lastly the judgers tend to formed conclusions quickly. This resulted to filtering credible web sites based on the format and layout of the websites.
\end{abstract}

\section{Introduction}

Reliance on the Internet as a source of information has increased dramatically in recent years among information seekers. On the other hand, the advent of Web technologies has created unprecedented opportunity for information producers to easily publish information [6]. The privilege of writing anonymously and the absence of an editorial function can lead people to often questionable or inaccurate information. These processes have created a need for examining the process of credibility evaluation by users. The credibility evaluation styles, however, might vary depending on the skills, experiences and learning style of the user [9]. This study attempts to have a more in depth look at the effect of one particular individual difference, personality, on performing credibility evaluations of Web pages.

\section{Background}

Credibility is not a property of an object but a quality or perception ascribed to an object by the receiver of the information [9][10]. There are two components of credibility; trustworthiness and expertise. Trust is defined by the terms "wellintentioned, truthful, unbiased" [8, pp.1] meanwhile expertise, is defined by terms such as "knowledgeable, experienced, and competent"[8, pp.1]. Research in this area 
have identified various factors that can influence credibility judgement. Among the important factors taken into consideration in making credibility judgement are look and design of the page and ease of use. Web sites that look professional and that are easy to navigate are perceived as more credible by users[11]. Other tracks of research in this area examined the role of structural and message features in influencing the credibility evaluation by users [12][13]. Several structural features have been recognized to influence the perceptions of credibility. These include top-level domain name, navigation tools, presence of privacy policy statements, third-party endorsements, site ownership and site contact information [12] [13]. Message features like inclusion of quotes, testimonials, statistics disclosure of authorship, references, information currency (posted dates of content modification), have also been found to contribute to credibility perceptions [12] [13] [14].

Based on a number of large credibility studies, a theory called Prominence Interpretation Theory was later proposed[9]. In this theory Fogg argued that only the features noticed (prominence) by the users will be considered in making credibility evaluation. Many factors influence how these features will be noticed or perceived. Users' ability to scrutinize the information, the topic of information and the users' level of expertise can influence how the features of web sites are perceived. In addition, individual differences for example cultural background, cognitive and personality style may also influence how the features of web sites are perceived and factored into the credibility evaluation process.

Currently, studies that examined the impact of individual differences are still limited. Some researchers have examined the impact of expertice level towards credibility perception of web sites. Generally the findings suggested that novice users relied mostly on the visual and information design web sites and not on other features [1][14]. They were generally satisfied and comfortable when there was a lot of information presented in the web sites without much concern about the sources of information [1]. On the contrary, experts were more comprehensive in their credibility evaluation process. Besides the look and design of the page, they also focused on the name, affiliation and reputation of the Web Sites in judging the credibility of the site [1] [14]. These studies suggested that individual differences play an important role in influencing credibility evaluation styles. Thus our study attempts to examine how user characteristics, particularly their personality style, impact credibility judgments.

\section{Methodology}

Fifteen people have participated in this study. $70 \%$ of them were female while $30 \%$ were male. $86.7 \%$ were undergraduate students while the rest were graduate students. On average, participants spent 24.6 hours/week searching information from the Web.

Prior to the experiements, participants were required to fill out online questionnaires on their demorgaphic information, cultural background, computer and Web experience, and personality style. We adopted the Champagne and Hogan [4] personality style framework to classify the participants into four types of personalities: intuitive, judging, thinking, and perceiving.

The participants were asked to carry out several information seeking tasks. Three tasks were prescribed for them and one was defined in collaboration with the 
participants to reflect a more realistic task. The first task was a known-item informationseeking task. This task served as a warm-up period for the participants and the answer was on purpose easy to find. The next two tasks were medium-complexity tasks, one in English and one in Spanish. Both concerned travel planning to a given destination for a certain amount for time. The third task was based on a real task of the participant and was also a topic-driven task. While the participants were searching, their activities were recorded.

For each task, participants were required to select five websites as relevant and bookmark these. Out of these, they were asked to select one that they perceived as the most credible and they rated the credibility components like believability, accuracy, trustworthiness, bias, and completeness of the information in a questionnaire [2] [7]. All items were measured on a five-point scale. Participants also rated the web sites along several dimensions that have been shown to impact credibility such aesthetic appeal, organization of information, timeliness of information, validity of information, matching information needs, matching prior expectations, literary appeal, and profit purpose appeal [10][11][12][13][14].

At the end of the session the participants were interviewed about their general credibility evaluation process. They were asked about the frequency, methods, and criteria of their web credibility evaluation behavior.

\section{Analysis}

Based on the participants' responses on the personality questionnaires, we identified their strongest personality dimension. Based on their definite strength scores, we then classified them into five different personality groups; Judging $(\mathrm{N}=4)$, Thinking $(\mathrm{N}=$ $3)$, Perceiving $(\mathrm{N}=2)$, Intuitive $(\mathrm{N}=3)$ and Sensing $(\mathrm{N}=1)$. We had to omit cases where there were no definite strengths identifiable based on their personality scores. Using the interview data, we performed open and axial coding [5] to identify the emergent trends and styles that participants used in performing credibility evaluation. This analysis is performed within similar personality groups and between different personality groups.

\section{Results and Discussion}

\subsection{Thinking Person}

Thinkers make judgments about life, people, occurrences, and things based on logic, analysis, and evidence, avoiding the irrationality of making decisions based on feelings and values [4]. Their personalities were reflected in their credibility evaluation styles. Evaluating credibility of web sites was something natural for the thinkers. They seemed to evaluate the credibility of websites almost every time they went to a site as described by one of our participants:

Every time I find something, it will subconsciously go to my mind that it's a credible website or not because I know what I look for, that makes something credible. 
Similarly, when another thinker was asked how frequently they performed credibility evaluation, one of them said:

I would say every time I looked at something

The thinkers also emphasized their verification of sources of information including the author competencies, as described by another participant:

They [the author] could be someone graduated from Stanford and CEO of this company and I said "ohh this could be credible", versus somebody who doesn't have a resume or I am not finding any searches about a particular person when they wrote this article.

(p14)

Our findings demonstrated that thinkers, reflective of their personality, often subconciously think about credibility when searching information from the websites. Their credibility evaluation style were also more fact based, involving verification of authors' background andexpertise, citations and reputation of the information sources.

\subsection{Perceiver Person}

The perceiver is a gatherer, always wanting to know more before deciding, holding off decision and judgments [4]. The following excerpt vividly demonstrates how an intutive participant still considered information from a potentially unreliable source, and used the information to find other credible pages that match her information needs:

Well first I went to Wikipedia to get an idea for what to look for Wikiepedia is not reliable all the time but it will give me an idea for what I could be looking for, and then looking at that [the Wikipedia] gives attractions that Sucre has, I went to Google and typed some stuffs. (p13)

As the participants in this group were more inclined to gather the whole perspetives, their evaluation style involved navigation from links to another links, helped them in judging the credibility of authors and information on the $\mathrm{Wb}$ sites:

I trust the links (references) from Wikipedia. Umm like a in the case of one researcher. He has links to his actual work. I did clicked the links to his articles, journals and it was credible journals.

Other traits of perceiver are open, flexible, adaptive, nonjudgmental, able to see and appreciate all sides of issues, always welcoming new perspectives and new information about issues [3] as quoted:

I usually turn to look at the websites outside the country from different perspectives

In performing credibility evaluations, participants belonged to this personality group, were not jumping into conclusion when noticing controversial information. They would verify the information with other sources. The excerpt below shows how our participant verified the information before reaching into conclusions: 
Well in the Wikipedia article said that he (the author) is under investigation for his violations of certain ethics. So I look more information about him.

Unlike the thinkers, perceivers were more tolerable to users' reviews and feedback allowing them to get information from various perscpectives before trusting the information on vendors'websites:

So I usually click on what's the most popular and what people usually buy. I often read the feedback, the problems they have, I try to look it up, too. What problem I would encounter too with the laptop or computer...I like to look up everything. I don't like to buy something without knowing. (pl)

Overall these findings suggested with respect to their personality style, participants in this group liked to have whole perspectives and considered various factors before believing the websites. They used information from different resources albeit some of them may not be reliable, and later evaluate those information to form their own credibility judgement.

\subsection{Intuitive Person}

The intuitive person thinks and discusses in spontaneous leaps of intuition that may leave out or neglect details [4]. Our observation suggested that the intuitive person relied much on the initial impression of the websites in making credibility judgment. The participant below explained why the web site is considered believable to her:

As far as my first impression is I see it is colorful, catches your eye with moving pictures.... I would say in general to helps draw my attention. The bright colors kind of make me want to read what it says.

The other participant also emphasized the initial impression in believing the web site:

It seems to be a very well organized, well-maintained website.

At the same time, they tended to rely on their familiarity of the web sites in making credibility judgment as demonstrated in the following quotes:

Any time I'm looking for information, and I find it on the sites that I'm not familiar with, I usually don't trust it much. I am more comfortable to go to the sites that I'm familiar with.

I used one that I am familiar and comfortable using and I know that it helped me to get from point a to point $B$ before. So I know that it's legitimate, it's credible

They also used their experience or prior knowledge in judging the websites:

If I've heard of it, but never use it before, I'm more likely to trust and use it a lot. 
The intuitive person becomes bored with nitty-gritty details, concrete, actual, and facts unrelated to concepts [4]. Unlike the perceivers, who considered the information from various perspectives, intuitive person paid less attention to supplemental information like user reviews and testimonials:

I learned that I have never really read a lot reviews because it's a matter of opinion.

These findings demonstrated that the intuitive evaluation styles were less fact based compared to the thinkers. Instead of focusing on detailed information, they relied mainly on their 'good feeling' of the web sites and their prior positive experiences with the web sites in making credibility judgement.

\subsection{Judging Person}

The judger is decisive, firm, and sure, setting goals and sticking to them [4]. People who had more orientation towards a judging personality are likely to come to conclusions quickly [3]. This behavior was reflected in their credibility evaluation as demonstrated below:

If it doesn't look professional, I immediately cut it off.

If it is a blog especially if it is something controversial than I don't usually take them as being credible.

I had troubled with it [the website] and I like to do things quickly so I would just give up on it and try another web site.

As judging person preferred structure and organization[3]; they placed great emphasis on the format and layout of the web sites in making credibility judgement. The excerpt below demonstrated the way they formed credibility judgement:

Ummm, it's poorly designed and you can tell there is barely any effort put in, usually if it's an organization they want to prove that you know something, especially if it is a big organization they want to put in something nice, usually the less aesthetically pleasing it is the less I'm likely to go to it.

The presentation is the first to look at. If I go to a website, the content is not well printed out, I do not really trust it.

Probably the first thing I want to stake out is the format.

\section{Conclusion and Future Work}

This study extends our understanding of the process of credibility judgments. We found personality styles to influence the process of credibility judgment and the recognition of features taken into consideration while making credibility judgments. We have demonstrated how thinkers' evaluation style was more fact based than 
intuitive participants' who relied more on their initial impression and prior experience with the websites. The perceivers gathered information from various sources before believing and forming a perception on the credibility of authors and websites. Lastly, the judgers tended to form conclusions quickly. This resulted in filtering credible web sites based on the format and layout of the websites. This study is still in progress and further data collection and analysis will be conducted.

\section{References}

1. Ahmad, R., Komlodi, A., Wang, J., Hercegfi, K.: The Impact of User Experience Levels on Web Credibility Judgment. In: Proceedings of American Society for Information Science and Technology, Pittsburgh (2010)

2. Austin, E.W., Dong, Q.W.: Source vs content effects on judgments of news believability. Journalism Quarterly 71, 973-983 (1994)

3. Briggs-Myers, I.: Myers-Briggs type indicator Palo A lot, 6th edn. Consulting Psychologists Press, CA (1999)

4. Champagne, D.W., Hogan, R.C.: Supervisory and Management Skills: A Competency Based Training Program for Middle Managers of Educational Systems (1979)

5. Corbin, J., Strauss, A.: Grounded theory research: Procedures, canons and evaluative criteria. Qualitative Sociology 13, 3-21 (1990)

6. Flanagin, A.J., Metzger, M.J.: The role of site features, user attributes, and information verification behaviors on the perceived credibility of Web-based information. New Media \& Society 9, 319-342 (2007)

7. Flanagin, A.J., Metzger, M.J.: Perceptions of Internet information credibility. Journalism and Mass Comm. Quarterly 77, 515-540 (2000)

8. Fogg, B.J., Tseng, H.: The Elements of Computer Credibility. In: Proceedings: Conference on Human Factors and Computing Systems (CHI), pp. 80-87 (1999)

9. Fogg, B.J.: Prominence-Interpretation Theory: Explaining how people assess credibility online. In: Proceedings: Conference on Human Factors in Computing Systems (CHI), pp. 722-723 (2003)

10. Fogg, B.J., et al.: What Makes Web Sites Credible? A Report on a Large Quantitative Study. In: Proceedings: Conference on Human Factors in Computing Systems (CHI), pp. 61-68 (2001)

11. Fogg, B.J., Soohoo, C., Danielson, D.R., Marable, L., Stanford, J., Trauber, E.R.: How do users evaluate the credibility of Web sites? A study with over 2,500 participants. In: Conference on Design for User Experience (2003)

12. Hong, T.: The influence of structural and message features on Web site credibility. Journal of the American Society for Information Science and Technology 57, 114-127 (2006)

13. Rains, S.A., Karmikel, C.D.: Health information-seeking and perceptions of website credibility: Examining Web-use orientation, message characteristics, and structural features of websites. Computers in Human Behavior 25, 544-553 (2009)

14. Rieh, S.Y.: Judgment of information quality and cognitive authority in the Web. Journal of the American Society for Information Science and Technology 53(2), 145-161 (2002)

15. Stanford, J., Tauber, E., Fogg, B.J., Marable, L.: Experts vs. Online Consumers: A Comparative Credibility Study of Health and Finance Web Sites (2002), http: / / www. consumerwebwatch.org/dynamic/web-credibilityreports-experts-vs-online-abstract.cfm 